\title{
The Implementation of Benchmarking in the Preparation of School Work Plan in Vocational High School
}

\author{
F. Ponco Sudaryanto ${ }^{1}$, Haryono ${ }^{2}$, Maman Rachman ${ }^{3}$, Titi Prihatin ${ }^{4}$ \\ ${ }^{1,2,3,4}$ Graduate School, Universitas Negeri Semarang, Indonesia \\ ${ }^{1}$ Corresponding email: foncosdaryanto@gmail.com
}

\begin{abstract}
Benchmarking implementation of school work plan is a form of andragogy learning, problem solving, continuous quality improvement, participated of school community in the school self-development, and task of quality assurance in the school. The aim of using performance benchmarking is that school needs analysis for arranging work plan. The research was conducted in Public Vocational High School 1 and 2 Manokwari. The benchmarking activities were conducted by implementing four steps: pre-preparation, preparation, implementation, and evaluation. This study gained data from the relevance, effectiveness (reaction), and satisfaction of learning outcomes. The data were collected by closed questionnaire of Kirk Patrick model, and data of test was used as learning result. Moreover, the analysis was done through $\mathrm{t}$-test. The results revealed the benchmarking material was relevant to the work of the respondents and it can be applied. The other finding showed that benchmarking effectively improved the quality of their work. Moreover, benchmarking increased the competency of respondents significantly. From effect size, benchmarking was more effective for women than men. Women's groups had better thinking than men. Self-evaluation benchmarking model could increase benchmarking competence and benchmarking adequately as a mode of expansion of school capacity in order to guarantee internal quality of school.
\end{abstract}

Keywords: benchmarking, school work plan, relevance, effectiveness, effect size

\section{Introduction}

One of the school's performances that gives the school strength is School Working Plan (RKS). The results of self-evaluation of schools in Vocational High School of Manokwari District obtained from LPMP (Education Quality Assurance Institute) West Papua in 2017 showed that the score of Education Management Standard Vocational was 6.291. Ideally, the score is obtained because the principal performs well in carrying out his leadership. The results of Vocational High School self-evaluation in Manokwari District for Management Standards reached 1.14 at the provincial level and 3.42 for the district level. This information indicated a problem gap in Vocational High School.

In relation to this condition, a model for implementation of school work plan based on selfevaluation is required by involving all school members and giving space to the school community to learn, to contribute in schools quality development, and to build a quality culture. Self-evaluation in the school can give base line data for continuous quality improvement (Matthews and Lave, 2003).

An urgent matter in education management system is the headmaster's commitment (commitment leadership) in order to realize the quality of education at the school level through the preparation of school work plans. In the education management cycle, planning takes an important role in the development of school capacity (Zohrabi and Manteghi, 2011). Planning, which involves various parties and solutions of all the needs of the school. It will ensure that school development is sustainable and fits the needs and demands of the school of its time. The preparation process of the school work plan is done through benchmarking.

This research focuses on managerial issues as follows:

1. Is benchmarking based on self-evaluation effective in the development of school capacity in an effort to conduct internal quality assurance?

2. How is the implementation model of benchmarking in the preparation of school work plans in an effort to perform quality assurance in vocational high school?

In general, the study aims to develop a collaborative school planning system for various reasons of limited school conditions or part of the work in schools. Specifically, this study aims as follows: (1) to examine the effectiveness of self- 
directed benchmarking in school capacity development and (2) to describe the model of benchmarking implementation in the preparation of school work plan as an effort to guarantee quality in vocational high school.

Planning is a managerial activity that taking thinking about the future. The planning aims continuously as part of efforts to improve a sustained quality of schools (continuous improvement). In addition, Wibawa points out the functions of planning are (1) as guidelines for implementation and control, (2) a tool to avoid waste of resources, (3) as a tool for the development of quality assurance and efforts to meet institutional accountability. Strategic planning is a planning that focuses on the vision and mission of the institution associated with the interests of stakeholders, taking into account the internal and external environment of the institution, and accompanied by studies of strategic issues for institutional development in the future (Wibawa, 2016; Lingam, Lingam, and Raghuwaija,2014).

The objective of benchmarking is to accelerate organizational learning in order to achieve a break-through in performance. Besides, it aims to engage in this approach to selfimprovement. A firm must first identify its own value-adding activities or processes that create its value chain. Then specific areas should be pinpointed for improvement (Tucker, 1987). The purpose of benchmarking is to align organizational performance through learning from experiences and achievements that have been achieved by others. Then, the researchers approached using self-improvement. Identifying added value and processing or creating values lead to achievement of work performance.

Most of Vocational High Schools are in disadvantaged conditions which has difficulty to make changes in a massive, consistent, and compliant manner. In order to get over the problem, the school needs for joint action with those who have succeeded. Susan et al. (2000) state that benchmarking school - to career as a strategy for whole - school reform. Then, Benchmarking is a school rearrangement strategy. Benchmarking is only a tool for improving the process and the final result. Through the implementation of benchmarking, the educational units can do a sustainable quality improvement and definitely have a positive impact on the development of a quality culture in the education units (Ajelabi and Tang (2010).

There are four steps in implementing benchmarking in the school: pre-preparation, preparation, implementation, and evaluation. The school planning model in the framework of quality assurance based on self-evaluation is focused on the planning (plan) conducted by using the following benchmarking procedures and steps.

\section{Methods}

This research examines the effectiveness of benchmarking workshop implementation in preparing school work plans based on school selfevaluation. Based on the assumptions above, the research involved two Vocational High Schools as the subject of this study. The study was imposed on two schools, namely SMK Negeri 1 and SMK Negeri 2 in Manokwari District, West Papua Province. Both Vocational High Schools were adjacent and managed in different fields. Generally, SMK Negeri 2 as a school which has the best practices (impactor) and SMK Negeri 1 as an impacted school. This study assumed that the best practices can be internal and/or external.

The focus or object of benchmarking was preparation of school planning such as (1) school management, includes: school structure, task details, self-evaluation, (2) School Work Program, (3) Curriculum Development, and (4) Extracurricular Activities. Data collected to gain the objectives of this study. Data required in this study includes Pre-test, Post-test, and benchmarking for reaction and learning. In addition, the source of data was a benchmarking participant.

Data collected using benchmarking material mastery tests in the form of pre-test and post-test. Reaction and learning data were collected using a closed questionnaire consisting of six items, as found in Kirk Patrick's model. Pre-test and Posttest are tailored to the material presented in benchmarking. The test is prepared by a benchmarking handling facilitator. While the questionnaire was translated from a questionnaire compiled by Kirk Patrick's model. Questionnaire consists of six items, points 1 and 6 measuring the reaction (reaction) and items 2, 3, 4, and 5 
measuring about learning (learning) (Ulum, 2014; Rafiq, 2015; Megan, 2016).

The research was conducted in SMK Negeri 2 Manokwari, followed by 71 teachers. The measurement of training success (benchmarking) can be seen from the effect size. To determine the effect size, Kirk Patrick formulations was used.

\section{Results and Discussions}

This research focuses on the process of preparing school planning by implementing benchmarking.

Table 1. Research Results Implementation of Benchmarking in Preparation of School Work Plan

\begin{tabular}{|c|c|c|c|}
\hline No. & Aspect & $\begin{array}{c}\text { Score } \\
\text { Average }\end{array}$ & Criteria \\
\hline 1 & $\begin{array}{l}\text { Basic } \\
\text { Development }\end{array}$ & 4,19 & Excellent \\
\hline 2 & $\begin{array}{l}\text { Benchmarking } \\
\text { Planning }\end{array}$ & 4,73 & Excellent \\
\hline 3 & $\begin{array}{l}\text { Benchmarking } \\
\text { Implementation }\end{array}$ & 4,90 & Excellent \\
\hline 4 & $\begin{array}{l}\text { Benchmarking } \\
\text { Evaluation }\end{array}$ & 4,66 & Excellent \\
\hline 5 & $\begin{array}{l}\text { Result of } \\
\text { Benchmarking }\end{array}$ & 4,50 & Excellent \\
\hline & Total Average & 4,6 & Excellent \\
\hline
\end{tabular}

Benchmarking based on rules that must be done by the school. Thus, principals, staff, and teachers have to believe that what is done has a solid foundation. Planning is done by involving all components of the school along with their respective duties. That is, their activities and participation in benchmarking are task activities that are their responsibility. The consequence of point that is their active participation in benchmarking activities. At the beginning of benchmarking, the committee/ organizer communicates the pretest and post-test score processing system.

The results of the limited benchmarking implementation test resulted in two groups of data, namely (1) evaluation to determine the relevance and effectiveness of benchmarking and (2) evaluation (pretest and posttest) to determine the improvement of competence. The data relating to the both evaluations are presented in the following sections.

\section{Reaction}

Reaction measured the things that trainees feel/think about and benchmark. There is something to be known through this reaction, that is the effectiveness of benchmarking and the relevance of benchmarking activities on the main task of the participants. Reaction is very important to examine in a training activity/ benchmarking because with a positive reaction will affect the learning process, attitudes and impact on the participants themselves as well as the institutions they represent. The result of data analysis by using Kirk Patrick model is presented as follows.

Table 2. Results of Reaction Analysis

\begin{tabular}{lcccccc}
\hline \multirow{2}{*}{ Criteria } & \multicolumn{6}{c}{ Percentage (\%) } \\
\cline { 2 - 7 } & $\mathbf{1}$ & $\mathbf{2}$ & $\mathbf{3}$ & $\mathbf{4}$ & $\mathbf{5}$ & $\mathbf{6}$ \\
\hline Excellent & 17.2 & 24.1 & 12.6 & 19.5 & 13 & 20 \\
Good & 75.9 & 70.1 & 54 & 59.8 & 69 & 55 \\
Average & 5.75 & 5.75 & 32.2 & 20.7 & 18 & 23 \\
Poor & 1.15 & 0 & 1.15 & 0 & 0 & 2.3 \\
Very Poor & 0 & 0 & 0 & 0 & 0 & 0 \\
\hline
\end{tabular}

The reaction instrument consists of 6 items. The items 1 and 6 are items that measures relevance, and items $2,3,4$, and 5 measure the effectiveness of benchmarking. The evaluation was followed by 87 participants. Based on the data above, it was obtained the relevance score of $84.05 \%$ and the effectiveness score of $80.53 \%$. The data was derived from the average percentage of items that include relevance or effectiveness in both excellent and good criteria.

Among 93.1\% (from Excellent $=17.2 \%+$ Good $=75.9 \%$ ) of respondents stated that the content workshop presented in benchmarking is understood. $94 \%$ of the participants stated that the materials mastery of instructor presented were excellent. In terms of quality of benchmarking material, $13 \%$ of participants stated that the benchmarking material is $76.6 \%$. It is in line with the use of the method used in benchmarking, $79 \%$. The image provides data that all benchmarking activities are within the criteria of total $82 \% .75 \%$ of the participants stated that the benchmarking 
material could be applied in work which in their responsibility.

\section{Learning}

One of the indicators of the successful benchmarking is to increase knowledge and skills. The results of pre-test and posttest data processing taken from 71 participants are portrayed as follows.

Table 3. Average Score, Thinking, and SD Test on Benchmarking

\begin{tabular}{clccc}
\hline $\begin{array}{c}\text { No } \\
.\end{array}$ & \multicolumn{1}{c}{ Description } & $\begin{array}{c}\text { Pre- } \\
\text { test }\end{array}$ & $\begin{array}{c}\text { Post } \\
\text {-test }\end{array}$ & $\begin{array}{c}\text { Thinkin } \\
\mathrm{g}\end{array}$ \\
\hline \multirow{2}{*}{1} & Class Average & 36.3 & 59.4 & 23.10 \\
& & 9 & 9 & \\
2 & Female Group Average & 37.2 & 62.4 & 25.23 \\
& & 6 & \\
3 & Male Group Average & 35.3 & 55.8 & 20.50 \\
& Standard Deviation of & 12.5 & 8 & \\
4 & Class & 8 & & \\
& Standard Deviation of & 12.1 & & \\
5 & Female Group & 4 & & \\
& Standard Deviation of & 13.2 & & \\
6 & Male Group & 1 & & \\
\hline
\end{tabular}

The data in the table shows that there is an increasing score of benchmarking participants. Based on the class, there is an increase (thinking) of 23.10. The average of female group score is 25.23. The score is greater than the male group score of 20.50. Thus, women are much better than men. Moreover, to find out whether the competency improvement of participants is significant or not, it is necessary to test the correlation. The results of correlation between pretest and posttest of benchmarking participants.

Table 4. Correlation t-test for Test on Benchmarking

\begin{tabular}{clc}
\hline No. & \multicolumn{1}{c}{ Statistic } & Correlation \\
\hline 1 & Class t-test & $1.7229 \mathrm{E}-13$ \\
2 & Female Group t-test & $8.2139 \mathrm{E}-08$ \\
3 & Male Group t-test & $1.0442 \mathrm{E}-19$ \\
\hline
\end{tabular}

The impact can be seen thoroughly, however, it can also be differentiated by gender. The result of effect size analysis for all participants (class), group of women, and group of men as follows.
Table 5. Effect Size of Benchmarking Workshop

\begin{tabular}{clc}
\hline No. & \multicolumn{1}{c}{ Group } & Score \\
\hline 1 & Class effect size & 1.84 \\
2 & Female Group effect size & 2.08 \\
3 & Male Group effect size & 1.55 \\
\hline
\end{tabular}

In benchmarking obtained the effect size score of 1.84 class. The effect size of female group is bigger than male group, that is 2.08 for women and 1.55 for men.

The success apply benchmarking of the school work plan in workshop that assuring the benchmarking improving, effective and benefit for school work plan. (Dragolea and Cortile, 2009). Benchmarking is best Practices Fully Integrated into Process

The amount of instructor can be increased by fixing some components that have not been maximized and focus to the benchmarking benefit (Cole, 2011). The increasing performance participants can do with consultation and participation with key stakeholders as an important part of the strategic planning (Lingam, Lingam, and Rughawaiya, 2014).

Benchmarking motivate to learn by necessity, life-oriented, and experience are the source of learning Andragogy and learning satisfaction in particular, exploration of other related factors seem necessary in order to clarify the connection between Andragogy and learning satisfaction (Ekoto and Gaikwad, 2015; Buckley, 2010).

The benchmarking in planning has a positive impact on improving competence of benchmarking participants (Ajelabi and Tang, 2010). The benchmarking school can study about the learning outcomes, assessment criteria, and assessment tasks in common units of study from benchmarker school (Booth, 2013:8; Fieldman, 2010).

\section{Conclusion}

Based on the whole of research can be drawn conclusion as follows.

1. This study has confirmed that benchmarking based on self-evaluation is able to show itself 
as a mode of developing the capacity of schools as an effort to guarantee the quality of schools.

2. The implementation of benchmarking in the preparation of school work plans as an effort to ensure quality in Vocational High School includes the main steps, namely prepreparation, preparation, implementation, evaluation, benchmarking results.

\section{References}

Ajelabi, Ifeoluwa \& Yinshang, Tang. (2010). The Adoption of Benchmarking Principles for Project Management Performance Improvement. International Journal of Managing Public Sector Information and Communication Technologies (IJMPICT). 1(2). 1-8.

Booth, Sara. (2013). Utilising Benchmarking to Inform Decision-Making at the Institutional Level: A Research-Informed Process. Journal of Institutional Research, 18(1). 1-12.

Cole, Michael J. (2011). Benchmarking: Contemporary Modalities and Applications. Evaluation Journal of Australasia. 11(2) 4248.

Dragolea, Larisa and Cotirlea, Denisa. (2009). Benchmarking - a valid Strategy for the long term?. Annales Universitatis Apulensis Series Oeconomica, 11(2). 813-826.

Ekoto, Christian Eugene and Gaikwad,Prema. (2015). The Impact of Andragogy on Learning Satisfaction of Graduate Students. American Journal of Educational Research 3(11), 1378-1386.
Lingam,G., Lingam, N., and Raghuwaiya. (2014). Effectiveness of School Strategic Planning: The Case of Fijian Schools. International Journal of Social, Behavioral, Educational, Economic, Business and Industrial Engineering. 8(7). 2119-2125.

Matthews, H. Scott and Lave, Lester B. (2003). Using Input-Output Analysis for Corporate Benchmarking. Journal 10(2). 152-167.

Paull, Megan and Girardi, Craig Whitsed and Antonia. (2016). Applying the Kirkpatrick model: Evaluating an Interaction for Learning Framework curriculum intervention. Issues in Educational Research. 26 (3). 490-504.

Rafiq, Mehwish. 2015. Training Evaluation in an Organization using Kirkpatrick Model: A Case Study of PIA. European Journal of Business and Management. 7(25). 52-161.

Goldberger, Susan, Keough, Robert, and Almeida, Cheryl. (2000). Benchmarking for Success in High School Education. The LAB at Brown University. And Jobs for the Future (JFF).

Tucker, G.T., Seymour, M.Z., and Camp, C.C. (1987). How to measure yourself against the best. Harvard Business Review. 2-5.

Ulum, Ömer Gökhan. (2015). Program Evaluation through Kirkpatrick's Framework. Pacific Business Review International. 8 (1). 106111.

zohra, Basuki. (2017). Manajemen Pendidikan Teknologi Kejuruan dan Vokasi. Jakarta: Bumi Aksara.

Zohrabi, Abazar \& Manteghi, Nikzad. (2011). A Proposed model for strategic planning in educational Organizations. Procedia - Social and Behavioral Sciences. 28. 205-210. 